\title{
Syndemic Production of HIV Infection among Tanzanian MSM
}

Adeniyi Adeboye $^{1 *}$, Michael W Ross ${ }^{2}$, Michael J Wilkerson' ${ }^{1}$, Andrew Springer ${ }^{1}$, Hycienth Ahaneku³ ${ }^{3}$ Rafeek A Yusuf ${ }^{3}$, Titilope O Olanipekun ${ }^{3}$ and Sheryl McCurdy ${ }^{3}$

${ }^{1}$ Department of Health Promotion and Behavioural Sciences, The University of Texas School of Public Health, Houston, USA

${ }^{2}$ Program in Human Sexuality, Department of Family Medicine and Community Health, University of Minnesota, Minneapolis, USA

${ }^{3}$ Department of Epidemiology, Human Genetics and Environmental Sciences, The University of Texas School of Public Health, Houston, USA

\begin{abstract}
Tanzanian men who have sex with men (MSM) experience HIV disparity and are disproportionately vulnerable to psychosocial health problems together called SAVID (Substance abuse, childhood and adolescent sexual Abuse [CSA], anti-gay Violence, Internalized homonegativity [IH], and Depression). We applied syndemic theory to assess additive effects of the SAVID problems on HIV seropositivity among 300 MSM from two Tanzanian cities, who provided demographic, psychosocial health-problem, and HIV-status information. Prevalence rates of the problems were substance abuse during condomless sexual intercourse (37.3\%), a history of CSA (35.3\%), anti-gay violence $(22 \%)$, high $\mathrm{IH}(52.7 \%)$, and depression (58\%). Bivariate analysis showed a significantly positive "dose-response" relationship between the SAVID-problem count and HIV seropositivity: SAVID problems significantly increased the odds of HIV seropositivity (odds ratio, 1.42). This is the first study in sub-Saharan Africa to use syndemic theory to explore additive effects of coexisting psychosocial health problems on HIV seropositivity among Tanzanian MSM. Our results underscore the need for comprehensive HIV interventions targeting MSM.
\end{abstract}

Keywords: Men; MSM; HIV/AIDS; Syndemic; Sub-Saharan Africa; SAVID

\section{Introduction}

The devastating impact of HIV and its inextricable association with emerging psychosocial health problems among men who have sex with men (MSM) in sub-Saharan Africa (SSA) require a broad explanatory model rooted in the sociopolitical construction of the disease that extends beyond the existing biomedical HIV research paradigm.

The concept of "syndemic" was introduced to advance theoretical understanding of three essential elements of disease in biosocial contexts [1-25]. First, diseases tend to cluster among socially disadvantaged populations. Second, diseases interact to produce additive effects, and third, these additive effects have a negative impact on the health of marginalized people.

The utility of this theory has been explored in studies conducted among MSM in United States, China, Thailand, and recently among socially marginalized women in South Africa [5,8,11,13,17]. For example, Mustanski et al. documented high rates of clustering of regular binge drinking, violence, and substance abuse that significantly increase odds of HIV positivity (odds ratio [OR], 1.42) among sampled young American MSM [13]. However, an extensive search of the literature failed to find any study that has explored the utility of this theory among MSM in SSA.

Compelling evidences suggest existence of a disproportionate prevalence of HIV among Tanzanian MSM [3,18,26-29]. For example, in 2008, HIV prevalence in Zanzibarian general population was $0.20 \%$ but $12.3 \%$ among the MSM population [30,31].

Beyond disproportionate clustering of HIV prevalence, independent associations are found between HIV infection and IH depression substance abuse and between anti-gay violence and depression among Tanzanian MSM $[2,9,15,18,20]$. Although childhood sexual abuse (CSA) has been implicated in HIV transmission among behaviorally heterosexual men, there are no published reports of the rate of CSA or its syndemic potential specifically among Tanzanian MSM [21-28].

Syndemic theory is thus well suited for application in SSA MSM who are disproportionately affected by HIV and exposed to syndemicrelated adverse conditions. This study was designed to explore the prevalence, clustering, and additive effects of Substance abuse, CSA, Violence, IH, and Depression (SAVID) on HIV seroprevalence among sampled Tanzanian MSM.

We hypothesized that: (1) psychosocial health problems cluster positively and significantly to produce SAVID syndemic; (2) doseresponse relationship exists between SAVID syndemic and HIV seropositivity; and (3) that SAVID syndemic variable has an additive effect on HIV seropositivity in the sampled Tanzanian MSM.

\section{Methods}

This study used data collected from surveys conducted in Dar es Salaam (2012) and Tanga (2013), Tanzania. Dar es Salaam has a population of about 3 million and Tanga (midway between Dar es Salaam and Mombasa), about 280,000.

Two hundred MSM from Dar es Salaam and 100 MSM from Tanga were recruited to participate using respondent-driven sampling (RDS) $[21,23]$. RDS, a snowball sampling method, employs 'seed' individuals to refer who they know; the latter then refer individuals they know using a predetermined number of coupons throughout the network [7]. RDS is strategically used to collect data from hard to reach people like MSM whose homosexual behavior is stigmatized and categorized as illegal in Tanzania.

*Corresponding author: Adeniyi Adeboye, Department of Health Promotion and Behavioral Sciences, The University of Texas School of Public Health, Houston, USA, Tel: +447960266152; E-mail: adeboye05@yahoo.co.uk

Received August 14, 2017; Accepted September 21, 2017; Published September 23, 2017

Citation: Adeboye A, Ross MW, Wilkerson MJ, Springer A, Ahaneku H, et al (2017) Syndemic Production of HIV Infection among Tanzanian MSM. J Health Educ Res Dev 5: 228. doi: 10.4172/2380-5439.1000228

Copyright: ( 2017 Adeboye A, et al. This is an open-access article distributed under the terms of the Creative Commons Attribution License, which permits unrestricted use, distribution, and reproduction in any medium, provided the original author and source are credited. 
We recruited first wave of participants by identifying in each city, five seeds of different ages from different areas in order to achieve better representativeness. Each seed was given three coupons to recruit three other MSM. Each coupon had unique identification numbers linking it to the referring seed. To determine sampling equilibrium for age and education, characteristics of recruited participants were repeatedly compared to those of seeds. As we approached closing any seed, the number of coupons was reduced to two and coupons were not given to the last respondents in each seed. We attained equilibrium for education and age and targeted sample size of 200 in Dar es Salaam and 100 in Tanga after seven waves.

We used Mombasa HIV rates of $40 \%$ in exclusively gay and $10 \%$ in bisexual men [23]. With 40\% in Dar es Salaam group and 20\% in Tanga group, a minimum of 80 men was required in each group. However, anticipating that between group differences may be smaller-in the order of 25\% in Dar es Salaam and 13\% in Tanga-than in Mombasa, we calculated a total sample of 310 to obtain a power of $80 \%$ in each city.

The institutional review boards at The University of Texas Health Science Center (HSC-SPH-10-0033) and the Tanzanian National Institute for Medical Research (NIMR/HQ/R.8a/Vol.IX/1088) reviewed and approved this study.

\section{Measures}

Dependent variable is HIV seroprevalence, determined by testing biologic samples provided by participants. Two testing methods were used: Determine (Abbot Laboratories, USA), and Unigold (Trinity Biotech PLC, Ireland) for initial and confirmatory testing respectively.

\section{Independent variables}

Sociodemographic characteristics; age, employment status, income, educational attainment, age at sexual debut, status as identifying as gay but still having a meaningful sexual relationship with women, and importance of religion to the participant.

\section{Syndemic factors}

Substance abuse during condomless sexual intercourse: Participants who answered 'Yes' to, "How many of those times that you received anal sex and/or had insertive anal sex with all partners, and did not use a male condom, were you high or drunk?" determined the sum score of participants under the influence of substance use during condomless sexual intercourse.

- Childhood sexual abuse: CSA was defined by using the developmental classification system of Doll and colleagues [4]. This schema classifies an experience as abusive contingent on age of the child or adolescent, age difference between partners, whether anal penetration occurred, and whether force was involved. Age difference between partners was used to distinguish between peer and non-peer contacts. Any contact involving use of force was considered sexual abuse regardless of age. Participants were asked several questions: "Have you ever been forced or coerced to have sex with someone?" "How old were you when you were forced or coerced into having sexual contact with someone?" "How old was the person who first forced you or coerced you into having sexual contact?" "Was your first sex partner a man or woman?" "How old was your first sex partner?" 'Yes' answers to these questions were summed and used to determine whether participant experienced CSA.

- Level of anti-gay violence: To determine levels of violence, responses to questions about the four types of abuse were considered. Responses to, "Have you been the victim of physical violence or abuse, verbal abuse, moral abuse, and/or sexual abuse?" were dichotomized according to number of 'Yes' responses to each separate question, so a maximum score of 4 was possible. Level of violence was characterized as High-level if there were three or four 'Yes' answers and as Low-level if there were one or two 'Yes' answers. Cronbach's alpha score for this sample was 0.714 .

- Stigma (defined by IH score): IH is acceptance and internalization of negative attitudes toward one's own sexual orientation [24]. For this measure, an eight-item short version of the 28-item Reactions to Homosexuality Scale was used [19,27]. The short version uses a six-point Likert response scale ranging from 0 (strongly disagree) to 5 (strongly agree); total score will range from 0 to 40 . Use of this scale has been found reliable and valid in MSM populations in SSA $[20,22]$.

- Depression: Depression was measured using Patient Health Questionnaire-9 (PHQ-9), a validated instrument for measuring the nine diagnostic criteria that constitute depressive disorders according to the Diagnostic and Statistical Manual of Mental Disorders, $4^{\text {th }}$ Edition (DSM-IV) definition [1]. PHQ-9 has proven reliable and valid for diagnosing depression and measuring its severity; its reliability and validity have also been shown among SSA populations $[10,12]$. Subjects scored each of the nine diagnostic symptoms of DSM-IV depression on a scale from 0 (not present at all) to 3 (present nearly every day); total score ranges from 0 to 27 . Cronbach's alpha score for this sample is 0.867 .

- SAVID syndemic: This variable is the cluster consisting of the five individual psychosocial factors. SAVID syndemic was created by categorizing each subject into one of the following four mutually exclusive groups: (1) no reported experience of any of the five psychosocial factors, (2) one factor reported, (3) two factors reported, and (4) three or more factors reported. This is consistent with groupings employed by Stall et al. [28-31].

\section{Data analysis}

First, we examined prevalence of all variables. Second, because data on all psychosocial health problems were dichotomized, Pearson's chisquared test of association was employed to assess whether psychosocial health problems cluster to form the hypothesized SAVID syndemic. Bivariate relationships between each psychosocial health problems and HIV seropositivity were examined. Third, to test the hypothesis that there is a dose-response relationship between psychosocial health problems and HIV seroprevalence, chi-squared testing for associations was carried out to determine levels and significance of HIV status with different counts of SAVID syndemic factors $(0,1,2$ and 3 or more). Fourth, to test for synergistic effect of SAVID syndemic, logistic regression was employed, with SAVID syndemic as independent variable, HIV status as dependent variable, and with all other factors examined (age, employment, education level, importance of religion, and identifying as gay but still having a meaningful sexual relationship with women) included as control variables. Finally, a set of multivariate logistic regression models was employed to examine factors associated with higher levels of SAVID.

Because all models contained the same dichotomized independent variables, each model was used each time to predict outcomes of each psychosocial health problems and HIV infection. However, whenever a particular model predicted a health problem, measures of that health 
Citation: Adeboye A, Ross MW, Wilkerson MJ, Springer A, Ahaneku H, et al. (2017) Syndemic Production of HIV Infection among Tanzanian MSM. J Health Educ Res Dev 5: 228. doi: 10.4172/2380-5439.1000228

Page 3 of 7

problem were excluded from the list of psychosocial health problems (3). For instance, measures of depression were excluded from the model when the model predicted an association between depression and other psychosocial health problems. The criteria of alpha $=0.05$ and two-tailed statistical significance were used. All analyses were carried out using Statistical Package for the Social Sciences (SPSS) version 23 software.

\section{Results}

Table 1 summarizes characteristics of sampled 300 Tanzanian MSM. Slightly more than half (51.3\%) were younger than 23 years old. Literacy level among was high, with $62 \%$ reporting post-primary school educational and 38\%, primary school education. Employment rate was high, at $81 \%$. $58.3 \%$ self-identified as homosexual; $36 \%$ bisexual; $4 \%$ undecided; and $1.7 \%$ straight or heterosexual. However, of the straight, only $32.7 \%$ reported having sexual relationships and $67.3 \%$ never had sexual relationships with women. $14 \%$ of participants opted out from HIV rapid testing. Of those tested, $30.2 \%$ in Dar es Salaam and $11 \%$ in Tanga were HIV positive.

Psychosocial problems were prevalent. 37.3\% reported being high or drunk while having condomless sexual intercourse, $35.3 \%$ history of CSA, $22 \%$ high level of violence, $52.7 \%$ positive for high level of $\mathrm{IH}$, and $42 \%$ high level of depressive symptoms.

Table 2 presents unadjusted ORs of bivariate relationships between psychosocial problems and HIV seropositivity. Degree of clustering

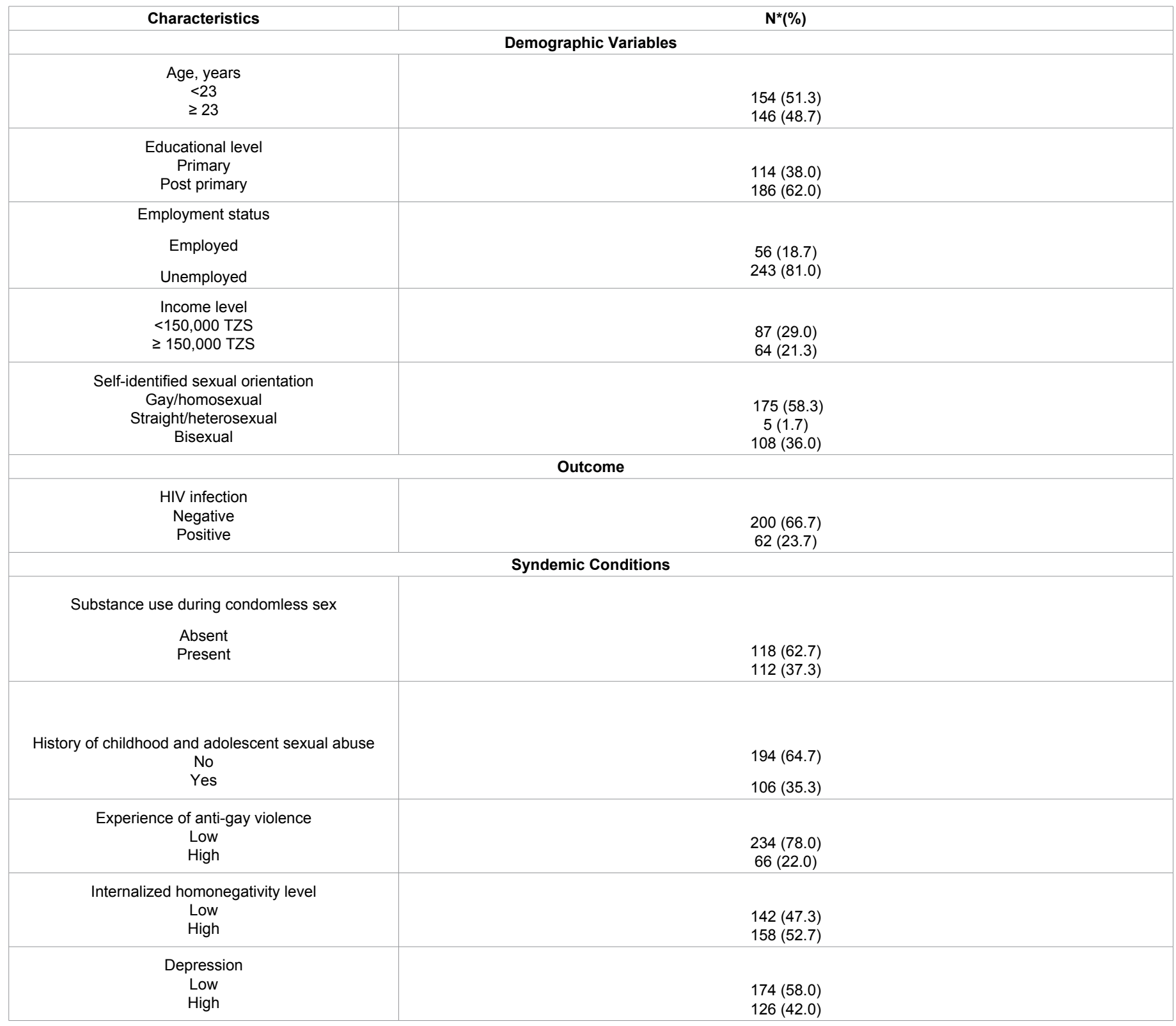


Number of syndemic conditions

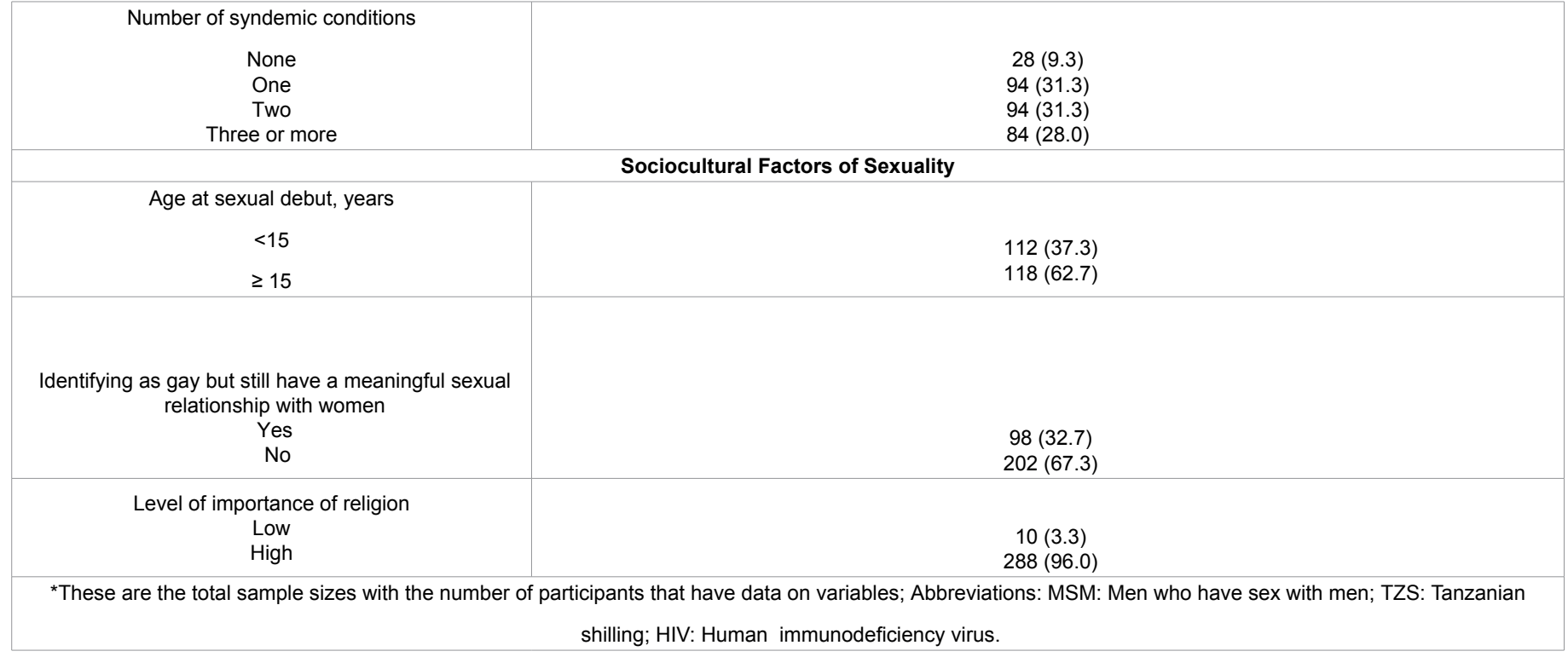

Table 1: Demographic, HIV prevalence and social characteristics of the 300 Tanzanian MSM in the study population: Tanzanian men's study: Dar es Salam, Tanga, 20122013.

of psychosocial problems among participants was high, as evidenced by eight of ten ORs being positive and statistically significant. For example, participants who reported being targets of anti-gay violence had 2.56 higher odds of experiencing $\mathrm{IH}(\mathrm{p}<0.001)$ than those who did not report being targets of violence.

Two bivariate relationships were not statistically significantly different, but their ORs were still positive - (1) MSM who reported being drunk or high while having condomless sexual intercourse and those with histories of IH; and (2) MSM with histories of CSA and those who reported being drunk or high while having condomless sexual intercourse.

Bivariate relationships between all psychosocial health problems and HIV infection were positive and statistically significant except - the relationship between substance use while having condomless sexual intercourse and HIV infection (OR, 0.80).

Table 3 presents significant relationships between number of psychosocial health problems and HIV infection. $28 \%$ of participants scored zero on the syndemic variable, $14.9 \%$ scored one, $18.5 \%$ scored two, and $39.1 \%$ scored three or more. Thus, having a greater number of coexisting psychosocial health problems was significantly and positively associated with a higher proportion of HIV seropositivity.

Table 4 presents outcomes of logistic regression models that examined relationship between SAVID and HIV seropositivity while controlling for sociodemographic variables. SAVID increased odds of HIV positivity (OR, 1.42; $\mathrm{p}=0.01$ ), but among all sociodemographic variables in the model, only one - a lower educational level - related with an increased risk of HIV positivity (OR, 2.04; $\mathrm{p}=0.01$ ).

In Table 5, predictors of each of the five SAVID syndemic conditions were examined by using multivariate logistic regression models. Six positive and significant $(\mathrm{p}<0.05)$ regression models based on Hosmer and Lemeshow test for goodness of fit were generated.

Whereas, Table 2 revealed that each syndemic condition was independently associated with one another, Table 5 reveals specified SAVID component uniquely and significantly associated with a given health problem after controlling for other factors in the model. For example, younger age, identifying as gay but still having a meaningful sexual relationship with women, younger age at sexual debut, high level of importance of religion, and violence were all positively and significantly related to a higher likelihood of having experienced CSA.

\section{Discussion}

Our results revealed a high degree of coexistence of SAVID psychosocial problems among this sample of Tanzanian MSM, evidenced by eight of ten bivariate associations being positive and statistically significant. The results also revealed the additive effect of SAVID, shown by the significant "dose-response" relationship between number of psychosocial health problems and HIV infection. Among our sampled participants, greater numbers of psychosocial problems were significantly associated with HIV seropositivity. Further, we found a significant and positive relationship between SAVID and HIV (OR, 1.42) while controlling for sociodemographic factors. A lower level of education was also significantly associated with HIV positivity (OR, 2.04). Hence, those who reported more psychosocial health problems were more likely to have been diagnosed with HIV infection. These findings are consistent with previous studies conducted among MSM in the United States, China, Thailand and among socially marginalized women in South Africa $[5,8,11,17]$.

Younger age and lower educational attainment were the only demographic factors found to be positively and significantly associated with violence and HIV positivity, respectively. However, among contextual factors examined, identifying as gay but still having a meaningful sexual relationship with women was significantly and positively related to CSA. Interestingly after controlling for demographic factors and other psychosocial health problems, IH was significantly associated with identifying as gay but still having a meaningful sexual relationship with women, depression, and violence. This supports evidence from previous studies which suggested that discordance between sexual behavior and sexual identity may be greatest among MSM who report a high level of stigma [6]. Notwithstanding controlling for other factors in the model predicting HIV seropositivity, the odds of being diagnosed with HIV infection 
Citation: Adeboye A, Ross MW, Wilkerson MJ, Springer A, Ahaneku H, et al. (2017) Syndemic Production of HIV Infection among Tanzanian MSM. J Health Educ Res Dev 5: 228. doi: 10.4172/2380-5439.1000228

Page 5 of 7

\begin{tabular}{|c|c|c|c|c|c|c|}
\hline Psychosocial Problem & $\begin{array}{c}\text { Substance Use } \\
\text { during Condomless } \\
\text { Sex }\end{array}$ & $\begin{array}{c}\text { Childhood and } \\
\text { Adolescent Sexual } \\
\text { Abuse }\end{array}$ & $\begin{array}{l}\text { Experience of Anti- } \\
\text { Gay Violence }\end{array}$ & $\begin{array}{c}\text { Internalized } \\
\text { Homonegativity }\end{array}$ & Depression & HIV Infection \\
\hline $\begin{array}{l}\text { Substance use during } \\
\text { condomless sex }\end{array}$ & - & & & & & \\
\hline $\begin{array}{c}\text { Childhood and } \\
\text { adolescent sexual } \\
\text { abuse }\end{array}$ & $1.10(0.81-1.48)^{\dagger}$ & - & & & & \\
\hline $\begin{array}{l}\text { Experience of anti-gay } \\
\text { violence }\end{array}$ & $1.82(1.38-2.41)^{\S}$ & $1.75(1.30-2.36)^{\ddagger}$ & - & & & \\
\hline $\begin{array}{c}\text { Internalized } \\
\text { homonegativity }\end{array}$ & $1.00(0.75-1.34)^{\ddagger}$ & $1.40(1.03-1.90)^{\ddagger}$ & $2.56(1.60-4.11)^{\S}$ & - & & \\
\hline Depression & $1.48(1.11-1.99)^{\S}$ & $1.61(1.18-2.18)^{\ddagger}$ & $2.76\left(1.75-4.40^{\S}\right.$ & $1.60(1.26-2.02)^{\S}$ & - & \\
\hline HIV infection & $0.80(0.56-1.14)^{\dagger}$ & $1.34(1.04-1.78)^{\ddagger}$ & $1.26(1.04-1.52)^{\S}$ & $1.68(1.17-2.43)^{\S}$ & $1.62(1.12-2.23)^{\S}$ & - \\
\hline
\end{tabular}

Table 2: Bivariate associations between psychosocial problems and HIV infection among the 300 Tanzanian MSM in the study population*: Tanzanian men's study: Dar es Salam, Tanga, 2012-2013.

\begin{tabular}{|c|c|c|c|c|c|}
\hline \multicolumn{6}{|c|}{ Number of Syndemic Conditions per MSM $(\mathrm{N}=300)$} \\
\hline \multirow{2}{*}{ HIV infection $(n=62)^{*}$} & $0(n=28)$ & $1(n=94)$ & $2(n=94)$ & $\geq 3(n=84)$ & $X^{2}(d f=3)$ \\
\hline & $28.0 \%$ & $14.9 \%$ & $18.5 \%$ & $39.1 \%$ & $14.245^{*}$ \\
\hline
\end{tabular}

Table 3: Percentages of HIV infection by number of syndemic conditions among the 300 Tanzanian MSM in the study population: Tanzanian men's study: Dar es Salam, Tanga, 2012-2013.

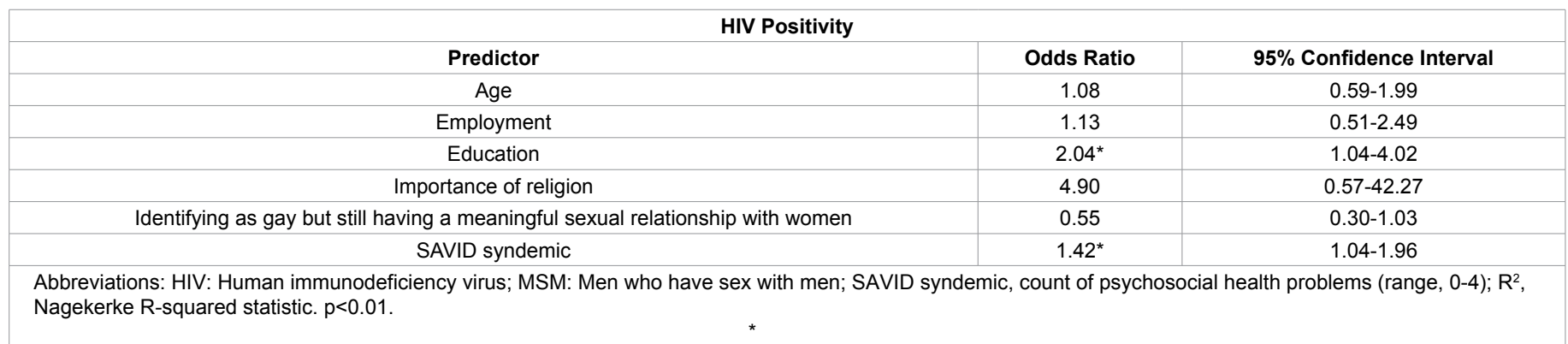

Table 4: Logistic regression models to evaluate the associations between the syndemic conditions and HIV Infection, controlling for demographic factors, among the 300 Tanzanian MSM in the study population: Tanzanian men's study: Dar es Salam, Tanga, 2012-2013.

\begin{tabular}{|c|c|c|c|c|c|c|}
\hline $\begin{array}{l}\text { Independent } \\
\text { Variable }\end{array}$ & $\begin{array}{c}\text { Substance } \\
\text { Use during } \\
\text { Condomless } \\
\text { Sexual Intercourse }\end{array}$ & $\begin{array}{c}\text { Childhood and } \\
\text { Adolescent Sexual } \\
\text { Abuse }\end{array}$ & $\begin{array}{c}\text { Experience of Anti-Gay } \\
\text { Violence }\end{array}$ & $\begin{array}{l}\text { Internalized } \\
\text { Homonegativity }\end{array}$ & Depression & HIV Infection \\
\hline Age $<23$ years & $\begin{array}{c}1.08 \\
(0.61-1.91)\end{array}$ & $\begin{array}{c}1.70 \\
(0.95-3.04) \dagger\end{array}$ & $\begin{array}{c}2.23 \\
(1.08-4.60) \ddagger\end{array}$ & $\begin{array}{c}0.90 \\
(0.53-1.60)\end{array}$ & $\begin{array}{c}0.69 \\
(0.39-1.21)\end{array}$ & $\begin{array}{c}1.05 \\
(0.55-2.01)\end{array}$ \\
\hline Employment & $\begin{array}{c}0.62 \\
(0.31-1.26)\end{array}$ & $\begin{array}{c}0.55 \\
(0.26-1.18)\end{array}$ & $\begin{array}{c}0.87 \\
(0.37-2.31)\end{array}$ & $\begin{array}{c}1.34 \\
(0.68-2.66)\end{array}$ & $\begin{array}{c}1.31 \\
(0.65-2.62)\end{array}$ & $\begin{array}{c}1.08 \\
(0.47-2.45)\end{array}$ \\
\hline Education & $\begin{array}{c}0.77 \\
(0.43-1.38)\end{array}$ & $\begin{array}{c}1.27 \\
(0.69-2.34)\end{array}$ & $\begin{array}{c}1.67 \\
(0.75-3.69)\end{array}$ & $\begin{array}{c}1.32 \\
(0.75-2.32)\end{array}$ & $\begin{array}{c}0.77 \\
(0.43-1.38)\end{array}$ & $\begin{array}{c}1.84 \\
(0.91-3.71) \dagger\end{array}$ \\
\hline $\begin{array}{l}\text { Identifying as gay but } \\
\text { still having meaningful } \\
\text { relationship with } \\
\text { women }\end{array}$ & $\begin{array}{c}0.95 \\
(0.52-1.73)\end{array}$ & $\begin{array}{c}1.90 \\
(1.02-3.53) \ddagger\end{array}$ & $\begin{array}{c}1.27 \\
(0.61-2.67)\end{array}$ & $\begin{array}{c}2.22 \\
(1.23-3.99) \ddagger\end{array}$ & $\begin{array}{c}0.96 \\
(0.53-1.75)\end{array}$ & $\begin{array}{c}1.51 \\
(0.78-2.91)\end{array}$ \\
\hline Age at sexual debut & $\begin{array}{c}0.51 \\
(0.23-1.14)\end{array}$ & $\begin{array}{c}8.13 \\
(1.82-36.34)\end{array}$ & $\begin{array}{c}0.63 \\
(0.19-2.09)\end{array}$ & $\begin{array}{c}1.40 \\
(0.64-3.05) \dagger\end{array}$ & $\begin{array}{c}2.38 \\
(0.97-5.83) \dagger\end{array}$ & $\begin{array}{c}1.42 \\
(0.48-4.15)\end{array}$ \\
\hline $\begin{array}{l}\text { High importance of } \\
\text { religion }\end{array}$ & $\begin{array}{c}1.03 \\
(0.24-4.48)\end{array}$ & $\begin{array}{c}9.67 \\
(2.1-42.78) \S\end{array}$ & $\begin{array}{c}0.20 \\
(0.04-0.97) \ddagger\end{array}$ & $\begin{array}{c}1.05 \\
(2.23-4.82)\end{array}$ & $\begin{array}{c}2.49 \\
(0.51-12.22)\end{array}$ & $\begin{array}{c}7.12 \\
(0.76-66.39) \dagger\end{array}$ \\
\hline $\begin{array}{l}\text { Substance use during } \\
\text { condomless sexual } \\
\text { intercourse }\end{array}$ & - & $\begin{array}{c}0.93 \\
(0.50-1.72)\end{array}$ & $\begin{array}{c}2.67 \\
(1.34-5.29) \S\end{array}$ & $\begin{array}{c}0.64 \\
(0.36-1.14)\end{array}$ & $\begin{array}{c}1.40 \\
(0.79-2.50)\end{array}$ & $\begin{array}{c}1.22 \\
(0.63-1.58)\end{array}$ \\
\hline $\begin{array}{c}\text { Childhood and } \\
\text { adolescent sexual } \\
\text { abuse }\end{array}$ & $\begin{array}{c}0.92 \\
(0.5-1.68)\end{array}$ & - & $\begin{array}{c}2.77 \\
(1.36-5.66) \S\end{array}$ & $\begin{array}{c}1.04 \\
(0.58-1.87)\end{array}$ & $\begin{array}{c}1.46 \\
(0.81-2.62)\end{array}$ & $\begin{array}{c}1.50 \\
(0.77-2.89)\end{array}$ \\
\hline
\end{tabular}




\begin{tabular}{|c|c|c|c|c|c|c|}
\hline $\begin{array}{c}\text { Experience of } \\
\text { anti-gay violence }\end{array}$ & $\begin{array}{c}2.68 \\
(1.35-5.30) \ddagger\end{array}$ & $\begin{array}{c}0.36 \\
(0.18-0.74) \S\end{array}$ & - & $\begin{array}{c}2.46 \\
(1.20-5.07) \ddagger\end{array}$ & $\begin{array}{c}1.85 \\
(0.93-3.71) \dagger\end{array}$ & $\begin{array}{c}1.56 \\
(0.74-3.29)\end{array}$ \\
\hline $\begin{array}{c}\text { Internalized } \\
\text { homonegativity }\end{array}$ & $\begin{array}{c}1.75 \\
(0.95-3.22) \dagger\end{array}$ & $\begin{array}{c}1.16 \\
(0.61-2.19)\end{array}$ & $\begin{array}{c}2.38 \\
(1.16-4.89) \ddagger\end{array}$ & - & $\begin{array}{c}2.09 \\
(1.19-3.65) \ddagger\end{array}$ & $\begin{array}{c}0.54 \\
(0.28-1.04) \dagger\end{array}$ \\
\hline Depression & $\begin{array}{c}1.41 \\
(0.79-2.52)\end{array}$ & $\begin{array}{c}0.7 \\
(0.40-1.31)\end{array}$ & $\begin{array}{c}1.18 \\
(0.90-3.70) \dagger\end{array}$ & $\begin{array}{c}2.06 \\
(1.18-3.60) \ddagger\end{array}$ & - & $\begin{array}{c}1.98 \\
(1.03-3.78) \ddagger\end{array}$ \\
\hline HIV infection & $\begin{array}{c}0.92 \\
(0.47-1.79)\end{array}$ & $\begin{array}{c}0.69 \\
(0.35-1.33)\end{array}$ & $\begin{array}{c}1.43 \\
(0.67-3.07)\end{array}$ & $\begin{array}{c}1.82 \\
(0.95-3.49) \dagger\end{array}$ & $\begin{array}{c}1.99 \\
(1.05-3.79) \ddagger\end{array}$ & - \\
\hline
\end{tabular}

Abbreviations: HIV: Human immunodeficiency virus; MSM: Men who have sex with men; *Data are presented as adjusted odds ratios (95\% confidence intervals).

Each column represents a single and independent regression model; $\uparrow p<0.1 ; \ddagger p<0.01 ; \S p<0.001$

Table 5: Multivariate associations between intersecting psychosocial problems among the 300 Tanzanian MSM in the study population *: Tanzanian men's study: Dar es Salam, Tanga, 2012-2013.

were positive but not significantly associated with being gay but still having a meaningful sexual relationship with women.

The model predicting violence, revealed a significant association between the importance of religion to the subject and violence. Similarly, the model also showed those who rated their religion as being very important had lower odds of haven experienced anti-gay violence. The above confirm assertion by Opera and colleagues that the importance of religion could be an adaptive but not optimally healthy factor $[14,16]$.

We acknowledge limitations regarding interpreting the findings from this study. Respondent-driven sampling is an unbiased but non-probabilistic sampling method and thus reduces generalizability of our findings. In addition, recall bias from obtaining information from incidents of 6 months ago cannot be ruled out. Finally, the cross-sectional nature of the study precludes making any temporal associations.

\section{Conclusion}

This study extended the utility of syndemic theory to reveal existence of co-occurrence of psychosocial health problems among sampled Tanzanian MSM. The stated hypotheses were supported with findings from this study. There is high prevalence of psychosocial health problems among Tanzanian MSM. These health problems clustered together positively and significantly to produce SAVID among these men. A significant and positive "dose-response" relationship existed between SAVID and HIV seropositivity in the sample. Intervention(s) that address one or two of the psychosocial health problems may synergistically reduce odds of HIV seropositivity among these disadvantaged Tanzanian MSM.

\section{References}

1. Adewuya AO, Ola BA, Afolabi OO (2006) Validity of the patient health questionnaire (PHQ-9) as a screening tool for depression amongst nigerian university students. J Affect Disord 96: 89-93.

2. Anderson AM, Ross MW, Nyoni JE, McCurdy SA (2015) High prevalence of stigma-related abuse among a sample of men who have sex with men in tanzania: Implications for HIV prevention. AIDS Care 27: 63-70.

3. Dahoma M, Johnston LG, Holman A, Miller LA, Mussa M, et al. (2011) HIV and related risk behavior among men who have sex with men in zanzibar, tanzania: Results of a behavioral surveillance survey. AIDS Behav, 15: 186-192.

4. Doll LS, Joy D, Bartholow BN, Harrison JS, Bolan G, et al. (1992) Self-reported childhood and adolescent sexual abuse among adult homosexual and bisexual men. Child Abuse Negl 16: 855-864.

5. Dyer TP, Shoptaw S, Guadamuz TE, Plankey M, Kao U, et al. (2012) Application of syndemic theory to black men who have sex with men in the multicenter AIDS cohort study. J Urban Health 89: 697-708.
6. Ford CL, Whetten KD, Hall SA, Kaufman JS, Thrasher AD (2007) Black sexuality, social construction, and research targeting 'The down low' ('The DL') Ann Epidemiol 17: 209-216.

7. Heckathorn DD (1997) Respondent-driven sampling: A new approach to the study of hidden populations. Social Problems-New York 44: 174-199.

8. Jie W, Ciyong L, Xueqing D, Hui W, Lingyao, H (2012) A syndemic of psychosocial problems places the MSM (men who have sex with men) population at greater risk of HIV infection. PloS One 7: e32312.

9. Johnston LG, Holman A, Dahoma M, Miller LA, Kim E, et al. (2010) HIV risk and the overlap of injecting drug use and high-risk sexual behaviours among men who have sex with men in zanzibar (unguja), tanzania. Int J Drug Policy 21: $485-492$

10. Kroenke K, Spitzer RL, Williams JB (2001) The Phq-9. J Gen Intern Med 16 : 606-613.

11. McCarthy K, Wimonsate W, Guadamuz T, Varangrat A, Thienkrua W, et al (2010) Syndemic analysis of co-occurring psychosocial health conditions and HIV infection in a cohort of men who have sex with men (MSM) in Bangkok Thailand. International AIDS Conference, Bangkok, Thailand.

12. Monahan PO, Shacham E, Reece M, Kroenke K, Ong'or WO, et al. (2009) Validity/reliability of $\mathrm{PHQ}-9$ and $\mathrm{PHQ}-2$ depression scales among adults living with HIVIAIDS in western kenya. J Gen Intern Med 24: 189-197.

13. Mustanski B, Garofalo R, Herrick A, Donenberg G (2007) Psychosocial health problems increase risk for HIV among urban young men who have sex with men: Preliminary evidence of a syndemic in need of attention. Ann Behav Med 34: $37-45$.

14. Ntetmen Mbetbo J (2013) Internalised conflicts in the practice of religion among kwandengue living with HIV in douala, cameroun. Cult Health Sex 15: 76-87.

15. O'Leary A, Jemmott III JB, Stevens R, Rutledge SE, Icard LD (2014) Optimism and education buffer the effects of syndemic conditions on HIV status among african american men who have sex with men. AIDS Behav 18: 2080-2088.

16. Operario D, Smith CD, Kegeles S (2008) Social and psychological context for HIV risk in non-gay-identified african american men who have sex with men. AIDS Educ Prev 20: 347-359.

17. Pitpitan EV, Kalichman SC, Eaton LA, Cain D, Sikkema KJ, et al. (2013) Co-occurring psychosocial problems and HIV risk among women attending drinking venues in a south african township: A syndemic approach. Ann Behav Med 45: 153-162.

18. Ross MW, Anderson AM (2014) Relationships between importance of religious belief, response to anti-gay violence, and mental health in men who have sex with men in east africa. Periodical 25: 160.

19. Ross MW, Rosser B (1996) Measurement and correlates of internalized homophobia: A factor analytic study. J Clin Psychol 52: 15-21.

20. Ross MW, Kajubi P, Mandel JS, McFarland W, Raymond HF (2013) Internalized homonegativity/homophobia is associated with HIV-risk behaviours among ugandan gay and bisexual men. Int J STD AIDS 24: 409-413

21. Ross MW, Nyoni J, Ahaneku HO, Mbwambo J, McClelland RS, et al. (2014) High HIV seroprevalence, rectal STIs and risky sexual behaviour in men 
Citation: Adeboye A, Ross MW, Wilkerson MJ, Springer A, Ahaneku H, et al. (2017) Syndemic Production of HIV Infection among Tanzanian MSM.

who have sex with men in dar es salaam and tanga, tanzania. BMJ Open 4: e006175.

22. Ross MW, Smolenski DJ, Kajubi P, Mandel JS, McFarland W, et al. (2010) Measurement of internalized homonegativity in gay and bisexual men in uganda: Cross-cultural properties of the internalized homonegativity scale. Psychol Health Med 15: 159-165.

23. Sanders EJ, Graham SM, Okuku HS, van der Elst EM, Muhaari A, et al. (2007) HIV-1 infection in high risk men who have sex with men in mombasa, kenya. AIDS (London, England) 21: 2513-2520.

24. Shidlo A (1994) Internalized homophobia: Conceptual and empirical issues in measurement. Some of the Information in this Chapter was Presented at the Meeting of the American Psychological Association, New York, USA.

25. Singer M (1994) AIDS and the health crisis of the US urban poor; the perspective of critical medical anthropology. Soc Sci Med 39: 931-948.

26. Smith AD, Tapsoba P, Peshu N, Sanders EJ, Jaffe W (2009) Men who have sex with men and HIVIAIDS in sub-saharan africa. The Lancet 374: 416-422.
27. Smolenski DJ, Diamond PM, Ross MW, Rosser BS (2010) Revision, criterion validity, and multigroup assessment of the reactions to homosexuality scale. J Pers Assess 92: 568-576.

28. Stall R, Mills TC, Williamson J, Hart T, Greenwood G, et al. (2003) Association of co-occurring psychosocial health problems and increased vulnerability to HIVIAIDS among urban men who have sex with men. Am J Public Health 93 939-942.

29. Tanzania Commission for AIDS (TACAIDS), Zanzibar AIDS Commission (ZAC), National Bureau of Statistics (NBS), Office of the Chief Government Statistician (OCGS), ICF Inter-national (2008) Tanzania HIVIAIDS and malaria indicator survey 2007-08.

30. Thurston IB, Dietrich J, Bogart LM, Otwombe KN, Sikkema KJ, et al. (2014) Correlates of sexual risk among sexual minority and heterosexual south african youths. Am J Public Health 104: 1265-1269.

31. van Griensven F, Sanders EJ (2008) Understanding HIV risks among men who have sex with men in africa. Sex Transm Dis 35: 355-356. 